\title{
Perbandingan Acromio Axillo Suprasternal Notch Index dengan Tes Mallampati dalam Prediksi Sulit Intubasi di RSUP Haji Adam Malik Medan
}

\author{
Aryudina Dalimunthe, Asmin Lubis, Chairul Mursin \\ Departemen Anestesiologi dan Terapi Intensif \\ Fakultas Kedokteran Universitas Sumatera Utara RSUP Haji Adam Malik Medan
}

\begin{abstract}
Abstrak
Sistem penilaian Mallampati masih digunakan sebagai prediktor sulit intubasi pada pasien yang akan menjalani pembedahan elektif dengan anestesi umum intubasi di Instalasi Bedah Pusat, namun dinilai masih kurang tepat. Tujuan penelitian mendapatkan alternatif bagi pasien yang tidak dapat duduk sebagaimana pemeriksaan pada Mallampati, namun tetap memiliki akurasi yang baik sebagai prediktor sulit intubasi pada pasien yang akan menjalani pembiusan umum intubasi di Instalasi Bedah Pusat RSUP Haji Adam Malik Medan selain sistem penilaian Mallampati. Penelitian cross-sectional dilakukan pada Desember 2016Januari 2017. Sebanyak 101 pasien yang memenuhi kriteria inklusi dinilai menggunakan tes acromio axillo suprasternal notch index (AASI) dan Mallampati oleh 2 penilai berbeda ketika preoperatif di ruangan dan sulit intubasi dinilai ketika tindakan pembiusan dengan skor Cormack-Lehane. Analisis statistik menggunakan tabel $2 \times 2$ serta area under curve (AUC), dihitung juga sensitivitas, spesifisitas, nilai prediksi negatif dan positif dengan SPSS ver.22. Hasilnya 5 dari 101 pasien yang memenuhi kriteria inklusi didapati dengan sulit intubasi. Penilaian AASI pada penelitian ini memiliki kemampuan yang sangat baik dalam memprediksi sulit intubasi AUC 95,3\% (95\% IK: 85,9-100\%; p=0,001). Penilaian Mallampati memiliki kemampuan yang baik dalam memprediksi sulit intubasi AUC 79\% (95\% IK: 52,2-100\%; p=0,03). Simpulan, sistem penilaian AASI lebih akurat sebagai indikator sulit intubasi daripada tes Mallampati di Instalasi Bedah Pusat RSUP Haji Adam Malik Medan.
\end{abstract}

Kata kunci: Acromio axillo suprasternal notch index, Cormack Lehane, intubasi, Mallampati

\section{Comparison between Acromio Axillo Suprasternal Notch Index and Mallampati Test in Predicting Difficult Intubation in Haji Adam Malik General Hospital Medan}

\begin{abstract}
Mallampati scoring system is still used as a predictor on difficult intubation in patients undergoing elective surgery under general anesthesia intubation; however, it is still considered a less appropriate technique. This study aimed to acquire possible alternatives for disabled patients during Mallampati examination with good accuracy as a predictor of difficult intubation in patients who were going to undergo general anesthesia intubation at the Central Operating Theater (COT) of Haji Adam Malik General Hospital Medan. This was a cross-sectional study conducted in the period of December 2016-January 2017 on 101 patients who met the inclusion criteria. These patients were assessed using acromio axillo suprasternal notch index (AASI) and Mallampati tests by two different appraisers during their stay in the pre-operative ward and the intubation difficulty was assessed by Cormack-Lehane score. Statistical analysis was performed using $2 \times 2$ tables and area under curve (AUC). The sensitivity and specificity as well as the positive and negative predictive values were calculated using SPSS ver.22. Five out of 101 eligible patients were found in the category of difficult intubation, The AASI assessment in this study was revealed as having a very good ability to predict difficult intubation with AUC $95.3 \%(95 \% \mathrm{Cl}: 85.9-100 \%, \mathrm{p}=0.001)$ while the Mallampati scoring was found to have a good ability in predicting mortality with AUC 79\% (95\% Cl: $52.2-100 \%$, p=0.03). In conclusion, AASI scoring system is more accurate as a predictor of difficult intubation than Mallampati test at the Central Operating Theater of Haji Adam Malik General Hospital Medan.
\end{abstract}

Key words: Acromio axillo suprasternal notch index, Cormack-Lehane, intubation, Mallampati

Korespondensi: Aryudina Dalimunthe, dr., SpAn, Departemen Anestesiologi dan Terapi Intensif Fakultas Kedokteran Universitas Sumatera Utara RSUP H. Adam Malik Medan, Jl. Bunga Lau No. 17, Medan, Tlpn. 061- 8364-581, Email aryudina.dalimunthe.an@gmail.com 


\section{Pendahuluan}

Sulit intubasi merupakan hal tidak terduga yang mungkin saja dapat kita jumpai dan berakhir dengan kegagalan intubasi sehingga berakibat fatal bagi keselamatan pasien. Insidens sulit laringoskopi atau intubasi dilaporkan sebanyak 0,1-20,2\%, variasi ini berbeda pada tiap populasi dan kriteria yang digunakan. ${ }^{1}$

Insidens sulit intubasi pasien bedah yang dilakukan dengan anestesi umum ditemukan sebanyak 1-18\% dan didapatkan pasien dengan gagal intubasi sebanyak 0,05-0,35\%. Sulit intubasi dapat menyebabkan mortalitas sebanyak 600 orang di dunia setiap tahunnya, bahkan sampai $28 \%$ dari keseluruhan tindakan anestesi yang berhubungan dengan kematian akibat ketidakmampuan dalam ventilasi atau intubasi. ${ }^{2,3}$

Telah dilaporkan insidens kesulitan laringoskopi ataupun intubasi endotrakea pada pasien yang akan menjalani pembiusan bervariasi dari $1,5 \%$ sampai $8 \%$, untuk kesulitan intubasi sebesar $1-4 \%$ pada Cormack-Lehane derajat III, sedangkan kegagalan intubasi sebesar 0,05-0,35\% pada derajat III dan IV. ${ }^{4,5}$

Berbagai metode telah digunakan untuk memprediksi kesulitan ketika laringoskopi dengan membandingkan parameter individual menggunakan skor. Prediksi sulit intubasi pada evaluasi preoperasi telah dicoba oleh banyak peneliti menggunakan pemeriksaan fisik berdasar atas tanda anatomi seperti Mallampati, jarak interincisive, thyromental distance (TMD), jarak sternomental, upper lip bite test (ULBT), dan rasio jarak hyomental yang semuanya menunjukkan perbedaan sensitivitas dan spesifisitas masing-masing. ${ }^{1,2}$

Lundstrom dkk. ${ }^{6}$ mempublikasikan sebuah penelitian meta-analisis dari 55 studi dan melibatkan 177.088 pasien dan didapatkan hanya $35 \%$ pasien dengan kesulitan intubasi yang diidentifikasi sebagai Mallampati III atau IV. Nilai sensitivitas dari penelitian metaanalisis ini 0,35 dan nilai spesifisitas 0,39 dengan area di bawah kurva ROC sebesar 0,75.

Shiga dkk. ${ }^{7}$ melalui penelitiannya telah menganalisis 31 studi dengan melibatkan 41.193 pasien terhadap uji Mallampati dan mendapatkan nilai sensitivitas 0,49 dan nilai spesifisitas 0,86 dan area di bawah kurva receiver operating characteristic (ROC) 0,82 dengan prevalensi sulit intubasi 5,7\%.

Huh dkk. ${ }^{8}$ melakukan penelitian terhadap 213 pasien tentang prediktor diagnostik dari kesulitan laringoskopi. Hasil penelitian menunjukkan nilai sensitivitas 0,12; nilai spesifisitas 0,94; nilai positive predictive value (PPV) 0,2; dan negative predictive value (NPV) 0,88 pada Mallampati kelas 3 dan 4 .

Penelitian yang dilakukan Kamranmanesh dkk. ${ }^{1}$ meneliti acromio axillo suprasternal notch index (AASI) dengan Mallampati pada pasien operasi elektif di Labbafinejad Hospital (Iran) yang merupakan ras Kaukasoid. Dari hasil penelitian secara statistik didapatkan AASI yang lebih sensitif dan akurat dibanding dengan Mallampati. Ras Melayu berbeda dengan ras Kaukasoid karena rahang atas, rahang bawah, bibir atas, bibir bawah, dan gigi incisivus lebih maju dibanding dengan ras Kaukasoid. ${ }^{1,9}$

Pada operasi maxillofacial, sternomental distance memiliki nilai sensitivitas yang lebih tinggi sebagai prediktor sulit intubasi dibanding dengan thyromental distance dan Mallampati. ${ }^{10}$

Safavi dkk. ${ }^{11}$ juga melakukan penelitian yang membandingkan AASI dengan prediktor lainnya terhadap sulit intubasi, ternyata AASI memiliki ROC yang lebih tinggi signifikan dibanding dengan tes lainnya sehingga lebih baik dalam memprediksi sulit intubasi daripada mallampati. ${ }^{11,12}$

\section{Subjek dan Metode}

Desain penelitian ini menggunakan studi diagnostik cross-sectional. Penelitian ini dilaksanakan di Instalasi Bedah Pusat RSUP Haji Adam Malik Medan periode Desember 2016 sampai Januari 2017.

Populasi adalah seluruh pasien yang akan dilakukan tindakan pembedahan elektif dengan anestesi umum yang menggunakan tindakan intubasi di Instalasi Bedah Pusat 
RSUP. H. Adam Malik Medan. Subjek diambil dari pasien yang akan dilakukan tindakan pembedahan dengan anestesi umum di Instalasi Bedah Pusat RSUP. H. Adam Malik Medan yang telah memenuhi kriteria inklusi dan tidak termasuk eksklusi.

Dari perhitungan besar sampel minimal didapatkan jumlah subjek 101 orang. Teknik sampling yang digunakan, adalah non probability sampling dengan consecutive sampling. Subjek penelitian adalah pasien dewasa yang rencana pembedahan elektif menggunakan anestesi umum dengan intubasi endotrakeal dengan status fisik ASA I dan II. Subjek yang dipilih memiliki berat badan ideal. Pasien dengan kelainan anatomi airway, gangguan gerakan daerah leher, trauma, tumor pada jalan napas, memiliki keterbatasan membuka mulut $<3 \mathrm{~cm}$, dan dapat duduk tidak diikuksertakan menjadi subjek penelitian ini.

Subjek yang menjalani proses anestesi umum dengan GA-ETT diberikan premedikasi midazolam 0,05 mg/kgBB dan fentanil $2 \mathrm{mcg} /$ $\mathrm{kgBB}$, ditunggu onset selama 5 menit, kemudian induksi propofol $2 \mathrm{mg} / \mathrm{kgBB}$, dan pelumpuh otot atrakurium $0,5 \mathrm{mg} / \mathrm{kgBB}$, ditunggu onset selama 3 menit. Dalam sniffing position, pasien diberikan ventilasi tekanan positif dengan oksigen 100\% kemudian dilakukan laringoskopi oleh peneliti menggunakan blade Mackintosh. Penilaian Cormack-Lehane dilakukan langsung oleh peneliti pada saat intubasi dan dilakukan visualisasi laring dengan laringoskop dengan menggunakan

Tabel 1 Karakteristik Demografi

\begin{tabular}{lc}
\hline \multicolumn{1}{c}{ Karakteristik } & n=101 (\%) \\
\hline Jenis kelamin & \\
Laki-laki & $39(38,6)$ \\
Perempuan & $62(61,4)$ \\
Usia, rata-rata (SD), tahun & $41,46(13,4)$ \\
Berat badan, rata-rata (SD), kg & $62,43(5,4)$ \\
Tinggi badan, rata-rata (SD), m & $1,65(0,1)$ \\
BMI, rata-rata (SD), kg/m ${ }^{2}$ & $23,4(1,5)$ \\
ASA, n (\%) & \\
1 & $18(17,8)$ \\
2 & $83(82,2)$ \\
\hline
\end{tabular}

klasifikasi Cormack-Lehane.

\section{Hasil}

Subjek yang terlibat dalam penelitian ini berjumlah 101 orang pasien yang telah memenuhi kriteria inklusi dan tidak termasuk kriteria eksklusi. Subjek terbanyak perempuan berjumlah 62 orang $(61,4 \%)$. Usia rata-rata subjek adalah 41,46 tahun. Subjek kebanyakan merupakan pasien yang berasal dari divisi bedah saraf berjumlah 23 orang $(22,8 \%)$, bedah digestif sebanyak 18 orang $(17,8 \%)$, dan bedah onkologi sebanyak 17 orang $(16,8 \%)$.

Hasil pengukuran antropometri untuk berat badan, tinggi badan, dan BMI rata-rata berturut-turut adalah $62,43 \mathrm{~kg}, 1,65 \mathrm{~m}$, dan $23,4 \mathrm{~kg} / \mathrm{m}^{2}$. Mayoritas subjek $(82,2 \%)$ berada pada ASA 2.

Hasil penelitian menunjukkan mayoritas subjek 96 orang (95\%) termasuk dalam Cormack-Lehane 1-2 dan sisanya sebanyak 5 orang (5\%) termasuk Cormack-Lehane 3-4. Hasil penilaian Mallampati sebanyak 97 orang (96\%) termasuk dalam Mallampati 1-2 (mudah diintubasi), 4 orang (4\%) dengan Mallampati 3-4. Hasil pengukuran AASI diperoleh nilai terendah adalah 0,4 dan tertinggi 0,86 dengan rata-rata 0,44 . Nilai prediksi positif (PPV) AASI adalah $80 \%$ dan nilai prediksi negatif (NPV) 99\%.

AASI dalam studi ini memiliki kemampuan untuk memprediksi sulit intubasi. Dari hasil analisis menggunakan kurva ROC diperoleh

\section{Tabel 2 Hasil Penilaian Intubasi}

\begin{tabular}{lc}
\hline \multicolumn{1}{c}{ Karakteristik } & n=101 (\%) \\
\hline Mallampati & \\
Mudah Intubasi & \\
(Mallampati 1-2) & $97(96)$ \\
Sulit intubasi (Mallampati 3-4) & $4(4)$ \\
AASI & \\
Mudah intubasi & $95(94)$ \\
Sulit intubasi & $6(6)$ \\
$\begin{array}{l}\text { Cormack Lehane } \\
\text { Mudah intubasi } \\
\text { (Cormack-Lehane 1-2) }\end{array}$ & \\
$\begin{array}{l}\text { Sulit intubasi } \\
\text { (Cormack-Lehane 3-4) }\end{array}$ & $96(95)$ \\
\hline
\end{tabular}


Tabel 3 Sensitivitas, Spesifisitas, Positive, dan Negative Predictive Value dari AASI terhadap Kesulitan Intubasi

\begin{tabular}{ccccccc}
\hline \multirow{2}{*}{ AASI } & \multicolumn{2}{c}{ Intubasi } & Sensitivitas (\%) & Spesifisitas (\%) & NPP (\%) & NPN (\%) \\
\cline { 2 - 7 } & Sulit & Mudah & & & \\
\hline$\geq 0,49$ & 4 & 1 & 80 & 99 & 80 & 99 \\
$<0,49$ & 1 & 95 & & & & \\
\hline
\end{tabular}

Tabel 4 Sensitivitas, Spesifisitas, Positive, dan Negative Predictive Value dari Mallampati terhadap sulit Intubasi

\begin{tabular}{lcccccc}
\hline \multirow{2}{*}{ Mallampati } & \multicolumn{2}{c}{ Intubasi } & Sensitivitas (\%) & Spesifisitas (\%) & NPP (\%) & NPN (\%) \\
\cline { 2 - 6 } & Sulit & Mudah & & & & \\
\hline Sulit & 3 & 2 & 60 & 97,9 & 60 & 97,9 \\
Mudah & 2 & 94 & & & & \\
\hline
\end{tabular}

bahwa area di bawah kurva (AUC) adalah 95,3\% (95\% IK: 85,9-100\%; $p=0,001$ ).

Berdasar atas kurva sensitivitas dan spesifisitas pada Gambar 2 maka diperoleh nilai cut-off untuk AASI adalah 0,495 cm. Dengan cut-off point $0,495 \mathrm{~cm}$ maka didapatkan nilai sensitivitas AASI adalah $80 \%$ dan spesifisitas 99\%.

Dari hasil penelitian didapatkan sensitivitas metode Mallampati dalam memprediksi sulit intubasi sebesar $60 \%$, spesifisitas 97,9\%, NPP $60 \%$, dan NPN 97,9\%. Metode Mallampati dalam studi ini memiliki kemampuan

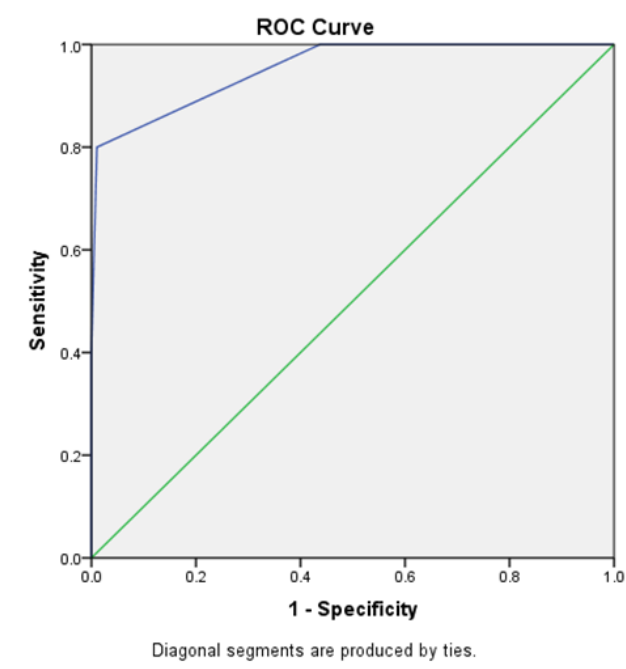

Gambar 1 Kurva ROC dari AASI terhadap Kesulitan Intubasi memprediksi sulit intubasi. Dari hasil analisis menggunakan kurva ROC diperoleh bahwa area di bawah kurva (AUC) adalah 79\% (95\% IK: 52,2-100\%; $p=0,03$ ).

\section{Pembahasan}

Karakteristik subjek berdasar atas jenis kelamin didapatkan total subjek laki-laki 39 orang $(38,6 \%)$ dan perempuan 62 orang $(61,4 \%)$ dengan body mass index (BMI) ratarata 23,4. Pada saat intubasi didapatkan 5 pasien dengan hasil Cormack-Lehane sulit

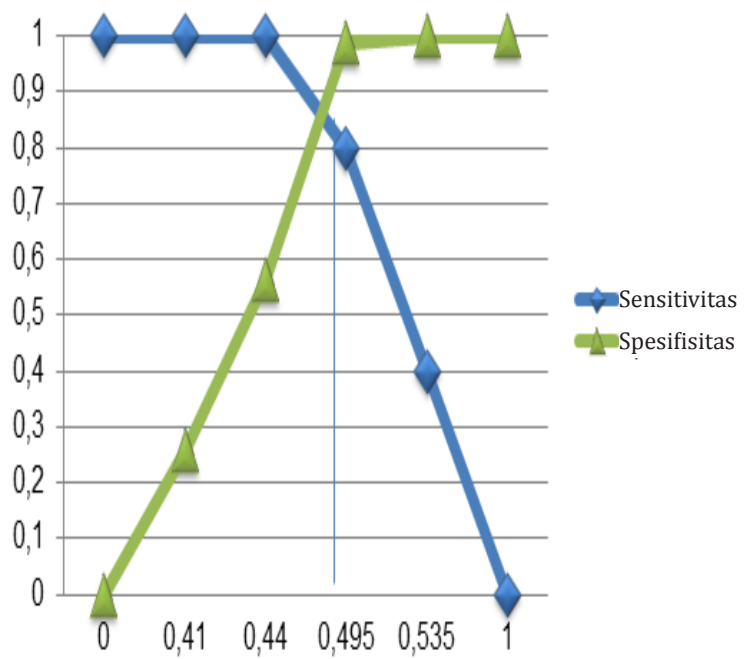

Gambar 2 Kurva Sensitivitas dan Spesifisitas AASI terhadap Sulit Intubasi 


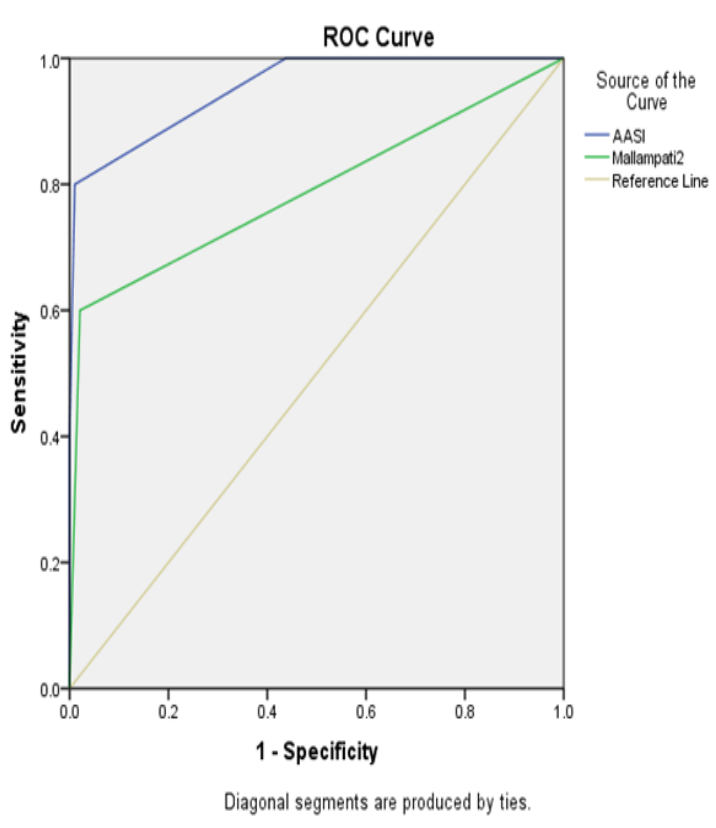

Gambar 3 Kurva ROC dari AASI dan Mallampati dalam Memprediksi Sulit Intubasi

intubasi, 3 pasien sesuai dengan prediksi sulit intubasi dengan penilaian AASI dan Mallampati, serta 2 pasien lagi sesuai dengan prediksi AASI walaupun mudah berdasar atas prediksi Mallampati. Sistem penilaian AASI memiliki kemampuan yang sangat baik untuk memprediksi kesulitan intubasi $(p=0,001)$. Dengan kurva ROC, diperoleh AUC adalah 95,3\% (95\% IK: 85,9-100\%; p=0,001). Cutoff point pada penilaian AASI ini adalah 0,495 sehingga didapat nilai sensitivitas sistem penilaian AASI dalam memprediksi kesulitan intubasi adalah $80 \%$ dengan spesifisitas 99\%.

Hasil penelitan menunjukkan perbedaan ukuran posisi pada soft palatum di orofaring, pada saat supine dan duduk sehingga pemeriksaan Mallampati pada posisi supine menjadi tidak akurat.

Cut-off point penelitian ini didapat berdasar atas kriteria dari skor Mallampati untuk prediksi mudah intubasi adalah skor Mallampati 1 dan 2, sedangkan prediksi sulit intubasi adalah skor Mallampati 3 dan 4. Sistem penilaian Mallampati pada penelitian ini memiliki kemampuan yang cukup dalam memprediksi sulit intubasi menggunakan kurva ROC diperoleh bahwa area di bawah

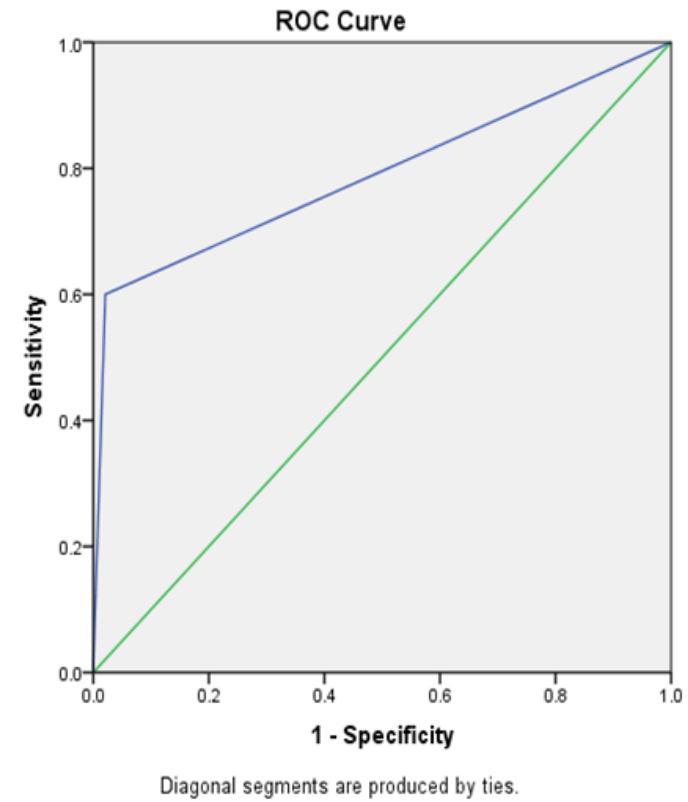

Gambar 4 Kurva ROC dari Mallampati terhadap Sulit Intubasi

kurva AUC sebesar 79\% (95\% IK: 52,2$100 \% ; \mathrm{p}=0,03$ ). Sensitivitas sistem penilaian Mallampati dalam memprediksi sulit intubasi sebesar $60 \%$ dengan spesifisitas 97,9\%. Dari penelitian yang dilakukan Kamranmanesh dkk. ${ }^{1}$ diperoleh nilai sensitivitas 52,4\% dan spesifisitas $85,7 \%$. Hal ini serupa dengan penelitian yang dilakukan Savafi dkk. ${ }^{12}$ dengan AUC $62,6 \%$, sensitivitas $47,6 \%$, dan spesifisitas $79,5 \%$.

Dari hasil penelitian ini diperoleh bahwa AUC kurva ROC sistem penilaian AASI memiliki luas yang paling besar (95,3\%), artinya sistem penilaian AASI memiliki kemampuan yang sangat baik sebagai prediktor sulit intubasi dibanding dengan sistem Mallampati. Selain mampu memberikan prediksi kesulitan intubasi yang baik, sistem penilaian AASI juga termasuk ekonomis dan praktis.

Dari pembahasan di atas didapatkan bahwa penilaian AASI memiliki validitas yang lebih tinggi jika dibanding dengan sistem penilaian Mallampati sebagai prediktor sulit intubasi pada pasien yang akan menjalani operasi elektif dengan anestesi umum di Instalasi Bedah Pusat RSUP Haji Adam Malik Medan. Oleh karena itu, sistem penilaian AASI dapat 
dijadikan sebagai prediktor sulit intubasi pasien yang akan menjalani operasi elektif dengan anestesi umum intubasi di Instalasi Bedah Pusat RSUP Haji Adam Malik Medan. Pada penelitian ini secara statistik sistem penilaian AASI memiliki luas AUC yang paling besar.

\section{Simpulan}

Dari pembahasan di atas didapatkan bahwa AASI lebih akurat sebagai indikator sulit intubasi daripada tes Mallampati.

\section{Daftar Pustaka}

1. Kamranmanesh MR, Jafari AR, Gharaei B, Aghamohammadi H, Zamany MP, Kashi AH. Comparison of acromioaxillosuprasternal notch index (a new test) with modified mallampati test in predicting difficult visualization of larynx. Acta Anaesthesiologica Taiwanica. 2013;1(1):141-4.

2. Wajekar AS, Chellam S, Toal PV. Prediction of ease of laringoscopy and inubation-role of upper lip bite test modified mallampati classification, and thyromental distance in various combination. J Family Med Prim Care. 2015;1(1):101-5.

3. Suhasini S, Mitali N. Predictors of difficult airway: preoperative assessment. J Evolution Med. 2016;36(5):2613-8.

4. Diemunsch P. Pottecher T. Predictive signs of difficult intubation. Int Anaesth Res Soc. 2016:1(1):169-80.

5. Mohan K, Rupa M. Comparison of upper lip bite test with thyromental distance for predicting difficulty in endotracheal intubation: a prospective study. Asian J Biomed Pharmaceut Sci. 2013;3(22):62-5.

6. Lundstrom LH, Vester-Andersen M, Moller AM, Charuluxananan S. Poor prognostic value of the modified mallampatiscore: a meta-analysis involving 177,088 patients. BJA. 2011;107(5):659-67.

7. Shiga T, Wajima Z, Tetsuo I, Sakamaoto A. Predicting difficult intubationin apparently normal patients. Am Soc Anaesthesiologists. 2005;103:429-37.

8. Huh J, Shin HW, Kim SH, Yoon TK, Kim DK. diagnostic predictor of difficult laringoscopy: the hyomental distance ratio. Anesth Analg. 2009;108(1):544-8.

9. Mohammad HA, Hassan A, Hussain SF. Cephalometric evaluation for Malaysian malay by steiner analysis. Sci Res Essays Malaysia Academic J. 2011;6(3):627-34.

10. Sutthiprapaporn $P$, Tanimoto $K$, Ohtsuka M, Nagasaki T, Lida Y, Katsumata A. Positional changes of oropharyngeal structures due to gravity in the upright and supine posiitions. Dentomaxillofacial Radiol. 2008;37(1):130-6.

11. Safavi M, Honarmand A, Hirmanpour A, Sheikhani Q, Jalali H. Acromio-axillosuprasternal notch index: a new screening test to predict difficult laryngoscopy in general population. J Anaesth Surg. 2016;3(4):1-6.

12. Safavi M, Honarmand A, Zare N. A comparison of the ratio of patient;s height to thyromental distance with the modified mallampati and the upper lip bite test in predicting difficult laringoscopy. Iran Saudi J Anesth. 2011;5(3):258-63. 